\title{
THE FATIGUE LIFE OF HEVEA AND GUAYULE RUBBERS
}

\author{
P. G. Santangelo, C. M. Roland* \\ Naval Research Laboratory, Chemistry Division, Code 6120, Washington, D.C. 20375-5342
}

\begin{abstract}
The enhanced crystallizability of guayule rubber (GR) in comparison to Hevea-based natural rubbers (NR) gives rise to better failure properties in unfilled, or "gum," GR. The origin of this behavior is the ability of the non-polymeric contaminants in GR to nucleate strain crystallization; a similar effect is operative in less pure grades of NR. However, when compounded with carbon black, this superiority of GR over NR is lost. The mechanical hysteresis arising from the carbon black, along with the latter's enhancement of strain crystallization, supercede the contribution from the contaminants. Consequently, in contrast to the behavior of the gum rubbers, the fatigue lifetimes of GR- and NR-based compounds are equivalent.
\end{abstract}

\section{INTRODUCTION}

The outstanding mechanical properties of natural rubber are due in large part to the polymer's capacity for strain-induced crystallization. ${ }^{1-9}$ More generally, the failure properties of an elastomer also reflect the presence of intrinsic flaws. ${ }^{10-16}$ Although compounding ingredients such as reinforcing fillers can influence the crystallization rate, ${ }^{17-20}$ they may also affect the size of intrinsic flaws. ${ }^{21-23}$ Thus, in formulating a natural rubber compound, consideration must be given, not only to obvious variables such as crosslink density and filler reinforcement, but also to their indirect effect on other factors influencing performance.

Natural rubber (NR) is available in a variety of standardized grades, differing in purity and viscosity. Typically about $2 \%$ by weight of NR consists of proteins, although these can be removed to yield a deproteinized version. ${ }^{24}$ Previously, we showed that those grades having more non-rubber contaminants are associated with larger intrinsic flaws; however, when compared at equal modulus, the less pure grades exhibited the best failure properties. ${ }^{25}$ This is contradictory, since flaws concentrate stress, thus promoting fracture and fatigue. However, these same non-rubber contaminants nucleate crystallization. Heterogeneous nucleation, in which crystallization commences at the surface of a microscopic, insoluble particle, is well-known for polymers in general, ${ }^{26,27}$ and for cis-1,4-polyisoprene in particular. ${ }^{28-34}$ This effect underlies one of the reputed advantages of deproteinized natural rubber, slower storage-hardening due to suppressed crystallization. By the same token, the enhancement of strain-crystallizability in standard grades of natural rubber can yield better failure properties. ${ }^{35}$

In this paper we describe a study of the failure properties of naturally-occurring cis-1,4polyisoprenes, both the common Hevea brasiliensis, NR, from rubber trees in southeast Asia, and guayule rubber, GR, obtained in North America from the shrub, Perthenium argentatum grey. During the first part of the twentieth century, before development of the Hevea rubber industry, the guayule shrub was a primary source of rubber for the United States ${ }^{36}$; however, presently there is no commercial production.

A number of reviews of the performance of guayule rubber have appeared, ${ }^{37-41}$ although a systematic study, in which the effect of the polymer are isolated from the effects of crosslink density and filler, is heretofore lacking. Generally, the physical properties of GR are reputed to be inferior to those of NR elastomers. ${ }^{41-44}$ Such a conclusion may be incorrect, an artifact of the

*Corresponding author. Tel: 202-767-1719; fax: 202-767-0594; e-mail: mike.roland@nrl.navy.mil 
different degree of crosslinking achieved when GR is substituted directly in a formulation for NR. We have shown that GR and NR of relatively low purity have better failure properties, at least as unfilled (gum) networks at a single crosslink density, than purer grades of natural rubbers. ${ }^{25}$ Such a result is due to the enhancement of strain-crystallization by the non-polymeric ingredients of the material. ${ }^{35}$ In the present work, we extend the comparison to rubbers having a range of crosslink densities, and also examine the effect of carbon black on the relative performance.

\section{EXPERIMENTAL}

Two Hevea rubbers were used, an ASTM D 2227 grade 10 (SMR-10, referred to herein as ribbed smoked sheet, "RSS") and a deproteinized natural rubber ("DPNR" from H. A. Astlett Co.). The DPNR is a purified form of natural rubber, having about $4 \%$ non-polymeric ingredients, versus ca. 7\% for a standard grade. The guayule rubber, "GR," was ASTM D 2227 grade 5 (provided by S. F. Thames of the Univ. of Southern Mississippi via the U.S. Dept. of Agriculture's Cooperative State, Research, Education and Extension Service). A series of peroxide cured networks were produced for each rubber, using from 1.0 to $3.5 \mathrm{phr}$ of dicumyl peroxide. Compression molded samples were cured for $60 \mathrm{~min}$ at $160^{\circ} \mathrm{C}$. Three sulfur-vulcanized networks of each polymer were also prepared, using the formulations and cure conditions listed in Table I. These vulcanized rubbers are designated RSS-A, -B, -C, DPNR-A, -B, etc.

All mechanical properties were determined at room temperature. Stress-strain data were taken with an Instron 4206 and optical extensometer (H.W. Wallace Co.), at an extension rate of 1.7\% per second. The strain energy was obtained from the retraction curve for the third cycle. Fatigue life measurements employed a Monsanto Fatigue to Failure Tester (ASTM D 4482-85) interfaced to a PC. A minimum of five specimens was tested at each strain, with the median value used for analysis.

TABLE I

Vulcanized Rubber Formulations

\begin{tabular}{|c|c|c|c|}
\hline & A & B & $\mathrm{C}$ \\
\hline cis-1,4-polyisoprene & 100 & 100 & 100 \\
\hline N220 & 70 & - & - \\
\hline N550 & - & 80 & - \\
\hline N660 & - & - & 65 \\
\hline Paraffin oil & 15 & 25 & 5 \\
\hline Zinc oxide & 5 & 5 & 5 \\
\hline Stearic acid & 2 & 2 & 2 \\
\hline Antioxidant $^{a}$ & 1.5 & 1.5 & 1.5 \\
\hline Sulfur & 1.5 & 2.5 & 2 \\
\hline $\mathrm{CBS}^{b}$ & 1.5 & - & 0.8 \\
\hline $\mathrm{TBBS}^{c}$ & - & 0.75 & - \\
\hline $\mathrm{TMTD}^{d}$ & - & - & 0.2 \\
\hline Cure & $15 \mathrm{~min}$ at $165^{\circ} \mathrm{C}$ & $15 \mathrm{~min}$ at $150^{\circ} \mathrm{C}$ & $10 \mathrm{~min}$ at $150^{\circ} \mathrm{C}$ \\
\hline
\end{tabular}

${ }^{a}$ Polymerized 2,2,4-trimethyl-1,2-dihydroquinoline (AgeRite ${ }^{\circledR}$ Resin D from RT Vanderbilt).

${ }^{b} N$-Cyclohexyl-2-benzothiazolesulfenamide (Flexsys Santocure ${ }^{\circledR}$ CBS).

${ }^{c} N$-tert-butyl-2-benzothiazolesulfenamide (Flexsys Santocure ${ }^{\circledR}$ TBBS).

${ }^{d}$ Tetramethylthiuram disulphide (Flexsys Perkacit ${ }^{\circledR}$ TMTD). 


\section{RESULTS}

\section{UNFILLED ELASTOMERS}

Fatigue lifetimes, $N$, were measured at $145 \%$ strain for peroxide-cured gum networks encompassing a range of crosslink densities. A basic tenet of fracture mechanics is that the failure properties are a unique function of the tearing energy (strain energy release rate), $T$. For uniaxial extension, the tearing energy is related to the recoverable strain energy by ${ }^{45,46}$

$$
T=2 k c W
$$

in which $c$ is the crack length. Test specimens herein were initially uncut; thus, this length corresponds to the intrinsic flaw size of the rubbers, $c_{0}$. Since $W$ represents the energy available for crack growth, it is best obtained from the stress-strain curve measured in retraction. ${ }^{47,48}$ The parameter $k$ is a slowly varying function of the strain, $\varepsilon$, given approximately by ${ }^{49,50}$

$$
k=\frac{\pi}{\sqrt{1+\varepsilon}}
$$

Over broad ranges of strain (for which oxidation is negligible), the crack growth rate (per cycle) can be expressed as a power law in terms of the tearing energy 45,46

$$
\mathrm{d} c / \mathrm{d} n=a T^{b}
$$

where $a$ and $b$ are material parameters. The exponent is reputed to be independent of compounding variables, assuming for natural rubber a value close to $2 .{ }^{51,52} \mathrm{~A}$ quadratic dependence was found for the present materials. ${ }^{25}$ Integration of Equation (3) gives an expression for the fatigue life for uniaxially strained rubber ${ }^{45,46}$

$$
N=\left[a(b-1) c_{o}^{b-1}(2 k W)^{b}\right]^{-1}
$$

For $b=2$, Equation (4) reduces to

$$
N=\left[a c_{o}(2 k W)^{2}\right]^{-1}
$$

Fracture mechanics analysis allows the intrinsic flaw size to be determined, either from measurement of the fatigue lifetime via Equation (4) if $a$ is known, or from the crack length dependence of the strain energy to break. Using the former method (since the present work is concerned with fatigue lifetimes), $c_{0}$ was deduced for the rubbers herein, ${ }^{25}$ and these results are given in Table II. There is no expectation that crosslinking will change the size of the inherent flaw, although it can affect an elastomer's response to flaws. ${ }^{23}$ Assuming $c_{0}$ is independent of crosslink density, Equation (5) can be applied to the fatigue data, enabling the cut growth constant, and its dependence on crosslink density, to be calculated for each of the three rubbers.

TABLE II

Results for UnFILled NATURAL RUbBers

\begin{tabular}{llc}
\hline Gum & $c_{0}, \mu \mathrm{m}^{a}$ & $b^{b}$ \\
\hline DPNR & 10 & 2.39 \\
RSS & 21 & 2.08 \\
GR & 26 & 2.03 \\
\hline
\end{tabular}

${ }^{a}$ Determined in reference 25 .

${ }^{b}$ Equation (4). 
These results, displayed in Figure 1, represent true material properties, independent of the details of the test method. The cut growth constant is observed to go through a minimum with respect to modulus (i.e., crosslink density). This well-known behavior reflects the compromise between greater structural integrity of the network as the gel point is traversed versus increasing brittleness at higher degrees of crosslinking. ${ }^{53-57}$ The best cut growth resistance (deepest minimum in Figure 1) is obtained with GR, which is also superior over a range of modulus values. DPNR exhibits the worst fatigue properties. These results are consistent with an earlier comparison of these rubbers at a fixed crosslink density (single value of modulus $=1 \mathrm{MPa}$ ) ${ }^{25}$ in which the failure performance was in the order GR $>$ RSS $>$ DPNR. This rank ordering parallels the strain-crystallizability of the rubbers, ${ }^{35}$ indicating that the non-polymeric contaminants nucleate crystallization. Consequently, to some extent, the contaminants govern the failure performance of the rubbers.

\section{CARBON BLACK FILLED ELASTOMERS}

It is not obvious that the better fatigue properties of GR as a gum network will be retained upon addition of reinforcing filler. Carbon black contributes substantially not only to the performance of amorphous elastomers, ${ }^{3,58-61}$ but to a lesser degree the failure properties of rubbers which straincrystallize ${ }^{62-64}$ The latter is due to promotion of strain crystallization by the carbon black. In filled rubber, it occurs more extensively and at smaller strains, ${ }^{17-19}$ as well as at a faster rate,${ }^{20}$ than for the corresponding gum. A preliminary finding suggested that the advantage of the less pure forms of NR is lost in the presence of filler. ${ }^{25}$

The comparison of the rubbers herein was extended to filled systems, using three formulations (Table I), representing both conventional sulfur vulcanizates (B and C) and a semi-EV cure (A), with various types of carbon black. These particular recipes were chosen because A, B, and C are reputed ${ }^{65}$ to have high, moderate and low fatigue lives respectively, while all compounds have

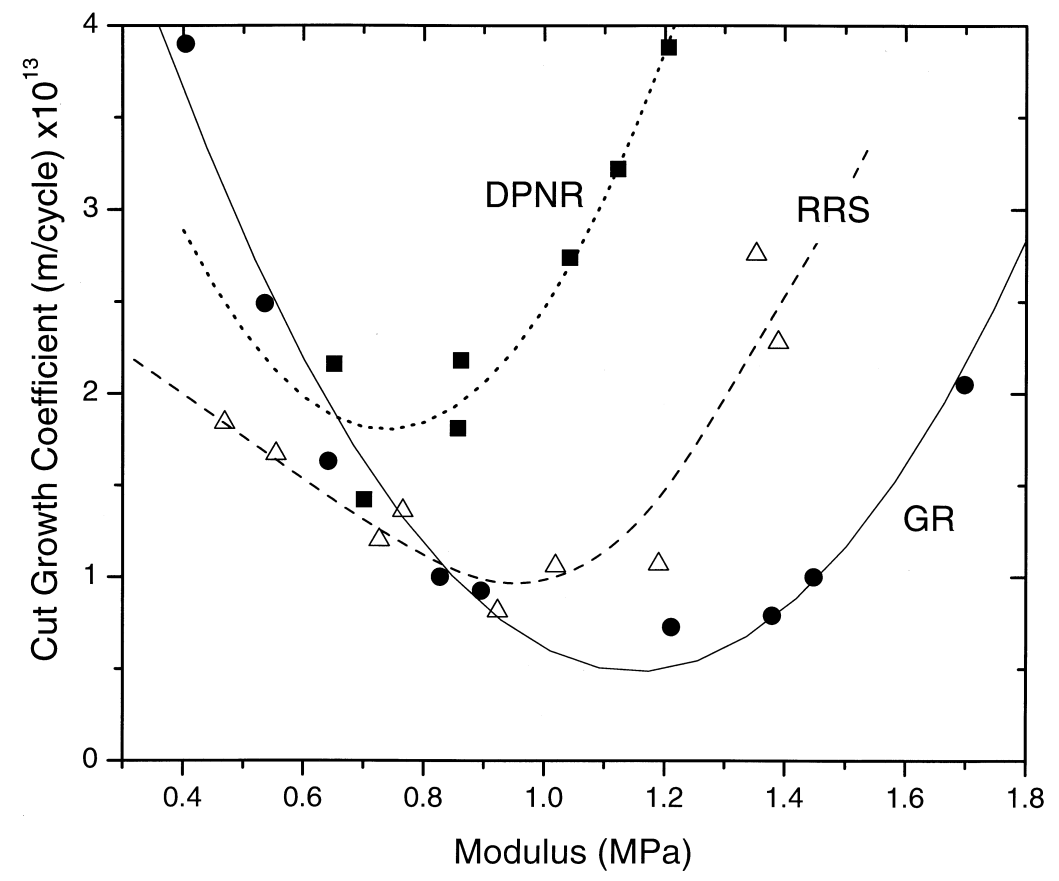

FIG. 1. - The cut growth parameter $a$ for the unfilled networks having varying crosslink density at $\varepsilon=1.45$, calculated using Equation (5) with $W$ in units of $\mathrm{J} / \mathrm{m}^{3}$ and $c_{0}$ in $\mathrm{m}$. 
TABLE III

Results for Filled Natural Rubbers

\begin{tabular}{lcccc}
\hline & Shore A durometer & 10\% Modulus, MPa & $100 \%$ Secant modulus, MPa & $b^{a}$, Eq. (4) \\
\hline DPNR-A & 74 & 1.23 & 0.84 & 1.3 \\
RSS-A & 75 & 1.45 & 0.96 & \\
GR-A & 74 & 1.25 & 0.86 & 1.4 \\
DPNR-B & 72 & 2.13 & 1.31 & \\
RSS-B & 72 & 2.02 & 1.20 & 1.7 \\
GR-B & 74 & 1.86 & 1.09 & \\
DPNR-C & 72 & 2.54 & 1.56 & \\
RSS-C & 71 & 2.76 & 1.67 & \\
GR-C & 74 & 3.03 & & \\
\hline
\end{tabular}

${ }^{a} \mathrm{~W}$ in units of $\mathrm{J} / \mathrm{m}^{3}$.

the same hardness. The latter is borne out in the durometer measurements obtained on the cured rubbers (Table III), which differ less than the reproducibility of the Shore A test (ca. 2 points ${ }^{66}$ ). At higher strains, the formulations exhibit substantial differences in modulus (Table III), although for a given compound these differences are no more than $15 \%$.

The fatigue lives were measured for each elastomer over a range of strains, and are plotted in Figures 2-4 as a function of the strain energy parameter $2 k W$ of Equation (4). Clearly, the fatigue life performance of each compound depends minimally on the type of natural rubber used; that is, the marked differences among the gum rubbers are lost when the elastomer is fully compounded. We also note that the cut growth exponents, $b$, in Table III for the filled rubbers are less than NR's usual value of 2 .

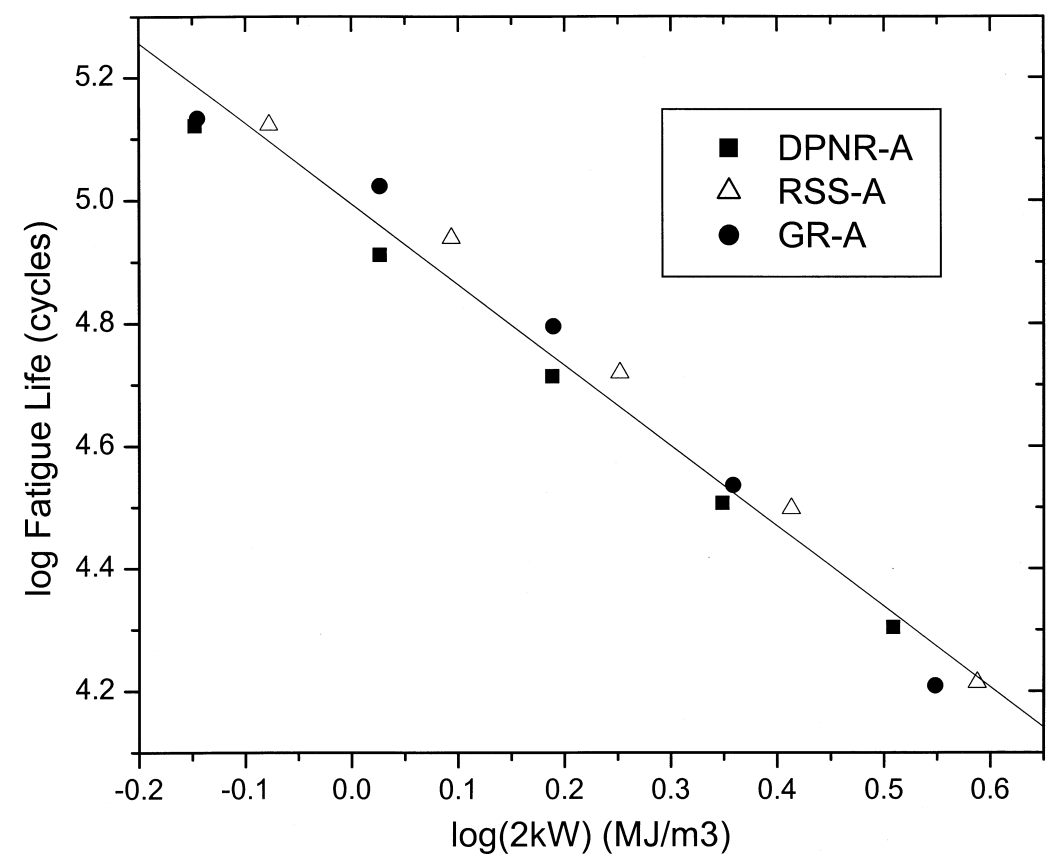

FIG. 2. - The cut growth constant as a function of the strain energy density factor, Equation (4), for each of the three rubbers using compound A. 


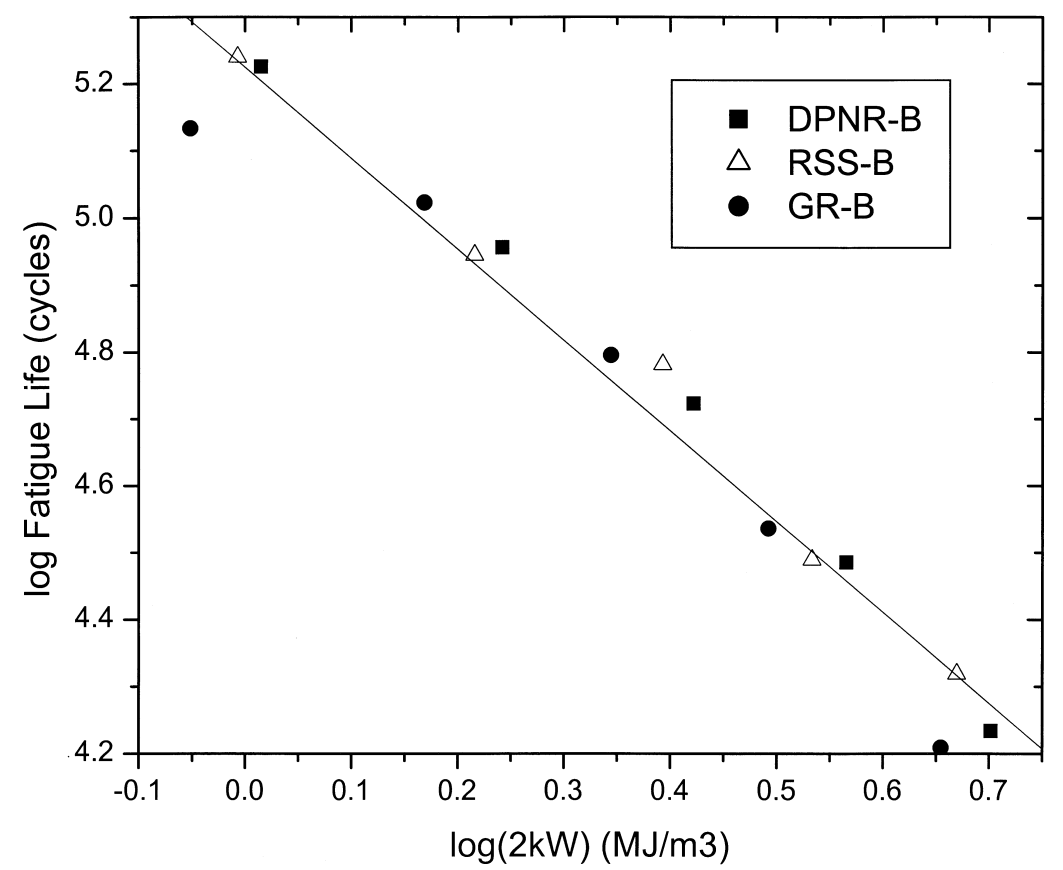

FIG. 3. - The cut growth constant as a function of the strain energy density factor, Equation (4), for each of the three rubbers using compound $\mathrm{B}$.

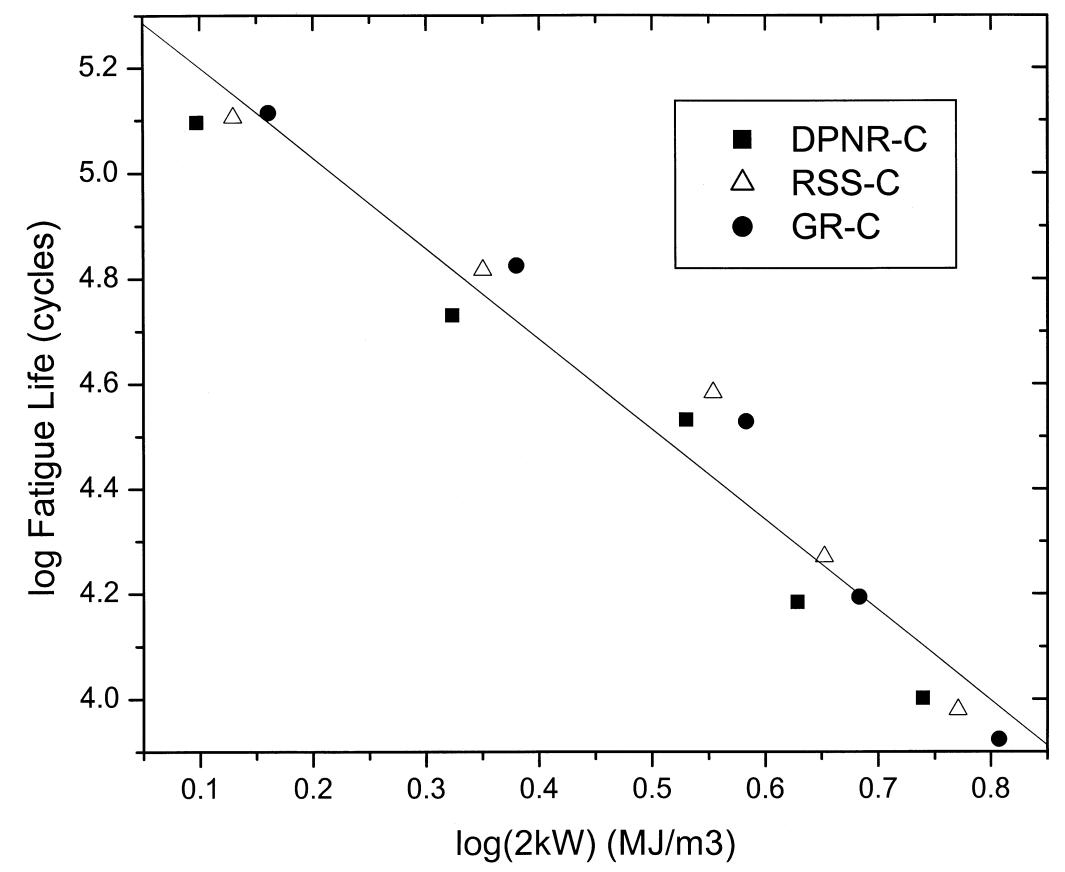

FIG. 4. - The cut growth constant as a function of the strain energy density factor, Equation (4), for each of the three rubbers using compound $\mathrm{C}$. 
The fatigue life depends on both the cut growth coefficient, $a$, and on the intrinsic flaw size, $c_{0}$, so that they cannot be determined independently from the data in Figures 2-4. Nevertheless, the fact that the three types of natural rubber all exhibit nearly the same behavior implies two things:

(i) The inherent flaw size, which in these gum rubbers varies as GR $>$ RSS $>$ DPNR, ${ }^{25}$ must be the same for each rubber compound. It is expected that the presence of carbon black will make the flaw size larger. For example, addition of $50 \mathrm{phr}$ of an HAF black increased $c_{0}$ by a factor of two in a sulfur-vulcanized NR. ${ }^{21}$ The intrinsic flaw size is also reported to scale in direct proportion to the surface area of the carbon black. ${ }^{22}$ Obviously, the filler can overwhelm any effect on flaw size arising from debris or other contaminants; hence, the differences in $c_{0}$ among the original polymers are lost upon incorporation of carbon black.

(ii) Strain crystallizability, which in the gum rubbers varies as GR $>$ RSS $>$ DPNR, ${ }^{35}$ must be equivalent when the rubbers are reinforced with carbon black. This is consistent with the well-known fact that strain crystallization is promoted by carbon black. ${ }^{17-20,25,35,67}$

Carbon black reinforcement of elastomers is due in part to the mechanical hysteresis arising from the polymer-filler and filler-filler interactions. ${ }^{9,45,68,69}$ When the hysteresis of the present compounds are compared (Figure 5), there is no difference among the three polymers. Carbon black dominates the mechanical hysteresis, and thus any variation in strain crystallizability among the rubbers does not lead to differences in properties. This is quite distinct from their behavior in the absence of filler (Figure 6). The gum rubbers only exhibit substantial hysteresis at large strains, associated with the onset of crystallization. ${ }^{35}$ Of course, the carbon black itself likely assumes the nucleating role of the non-polymeric contaminants, which are responsible for the enhanced crystallization of the gum GR. ${ }^{25,35}$

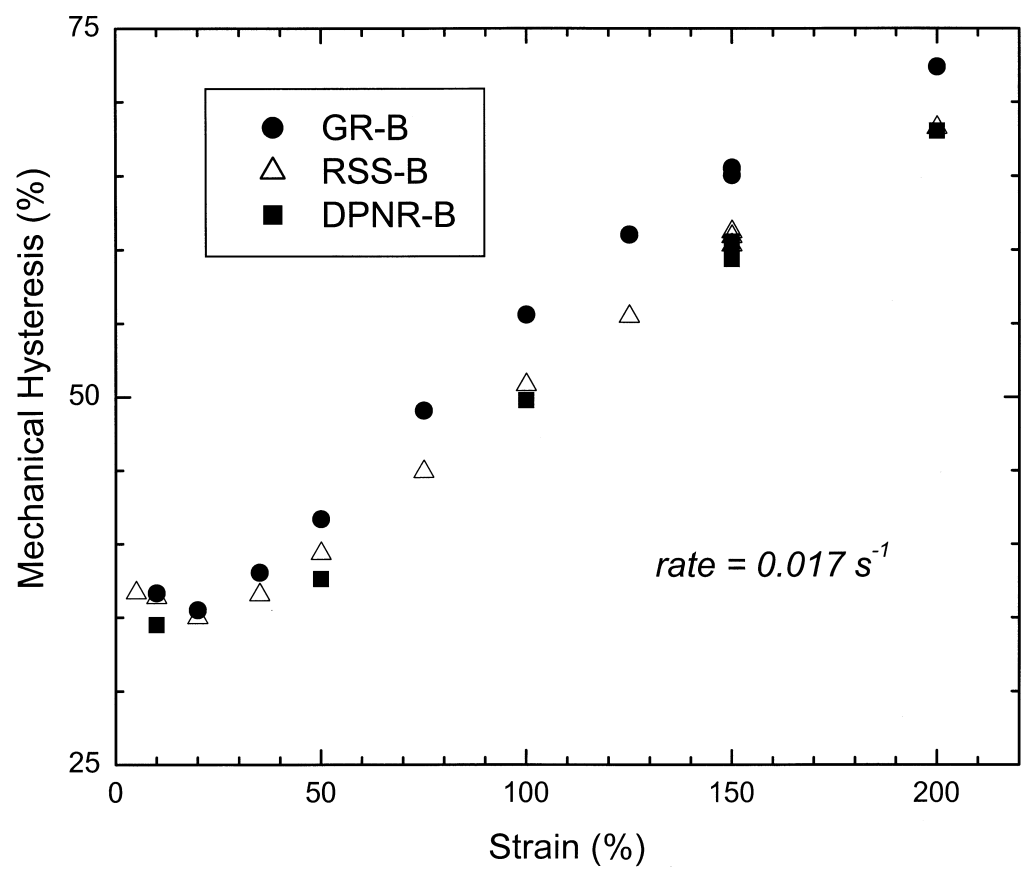

FIG. 5. - The area under the extension-retraction curve (third cycle) as a function of the maximum strain, for each of the three rubbers using compound $\mathrm{B}$. 


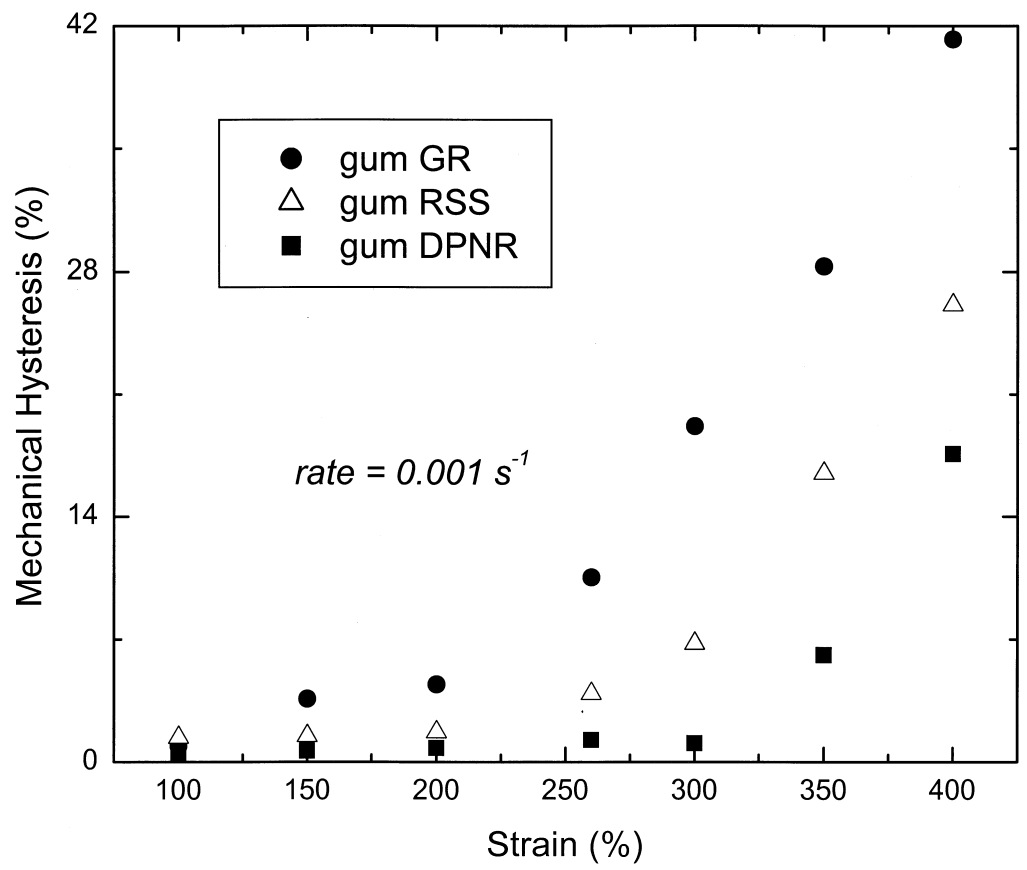

FIG. 6. - The area under the extension-retraction curve as a function of the maximum strain, for each of the rubbers without filler. The upturn in the vicinity of $\varepsilon=2.5$ is due to strain crystallization.

\section{CONCLUSIONS}

Previous work ${ }^{25}$ had shown that among naturally-occurring cis-1,4-polyisoprene networks lacking filler but having the same modulus, GR exhibits the best failure properties. More generally, failure performance exhibits a maximum as a function of degree of crosslinking. ${ }^{54-57}$ This is seen in Figure 1, in which an inverse quantity, the cut growth coefficient, goes through a minimum. Since the respective minima of different polymers do not coincide, a single point comparison, as made in reference 25, can be misleading. Nevertheless, the present study shows that for unfilled rubbers over a broad range of crosslink densities, GR is clearly superior to the Hevea rubbers. The origin of this behavior is GR's ability to crystallize at lower orientation, due to the nucleating effect of the nonpolymeric ingredients. ${ }^{35}$

This advantage of GR is not retained when reinforcing fillers are incorporated. Fatigue lifetimes of the compounded elastomers are independent of the particular naturally-occurring cis-1,4polyisoprene used. Carbon black's enhancement of the rubber's toughness negates any contribution from the non-polymeric ingredients in GR. Of course, since the effectiveness of reinforcing fillers depends on the severity of the crack growth, ${ }^{70}$ inferences drawn from the present results cannot necessarily be extended to more catastrophic failure processes.

\section{ACKNOWLEDGMENTS}

This work was supported by the U.S. Department of Agriculture, contract number 98-355046329.

\section{REFERENCES}

${ }^{1}$ J. Gough, Proc. Lit. and Phil. Soc. Manchester, 2nd Ser., 1, 288 (1805).

${ }^{2}$ J. E. Field, J. Appl. Phys. 12, 23 (1941).

${ }^{3}$ A. P. Aleksandrov and J. S. Lazurkin, Rubber Chem. TeChnol. 19, 42 (1946). 
${ }^{4}$ L. A. Wood and N. J. Bekkedall, J. Appl. Phys. 17, 362 (1946).

${ }^{5}$ G. Gee, J. Polym. Sci. 2, 451 (1947).

${ }^{6}$ B. V. Lukin and V. I. Kasatochkin, Rubber Chem. Technol. 21, 621 (1948).

${ }^{7}$ C. L. M. Bell, D. Stinson, A. G. Thomas, Rubber Chem. Technol. 55, 66 (1982).

${ }^{8}$ J. H. Magill, Rubber Chem. Technol. 68, 507 (1995).

${ }^{9}$ S. Toki, T. Fujimaki, and M. Okuyama, Polymer 41, 5423 (2000).

${ }^{10}$ F. Bueche, Rubber Chem. Technol. 32, 1269 (1959).

${ }^{11}$ M. Braden and A. N. Gent, J. Appl. Polym. Sci. 3, 100 (1960).

12 A. N. Gent, P. B. Lindley, and A. G. Thomas, J. Appl. Polym. Sci. 8, 455 (1964).

${ }^{13}$ H. W. Greensmith, J. Appl. Polym. Sci. 8, 1113 (1964).

${ }^{14}$ C. M. Roland and C. R. Smith, Rubber Chem. Technol. 58, 806 (1985).

${ }^{15}$ C. M. Roland and J. W. Sobieski, Rubber Chem. Technol. 62, 683 (1989).

${ }^{16}$ C. M. Roland, Rubber World 208, (3) 15 (June 1993).

${ }^{17}$ D. J. Lee, J. A. Donovan, Rubber Chem. Technol. 60, 910 (1987).

${ }^{18} \mathrm{H}$. Liu, R. F. Lee, and J. A. Donovan, paper no. 23 presented at a meeting of the Rubber Division, American Chemical Society, Cincinnati, OH, Oct. 18, 1988.

${ }^{19}$ S. D. Gehman and J. E. Field, Ind. Eng. Chem. 32, 140 (1940).

${ }^{20}$ A. N. Gent, Trans. Inst. Rubber Ind. 30, 144 (1954).

${ }^{21}$ G. J. Lake and P. B. Lindley, J. Appl. Polym. Sci. 9, 1233 (1965).

${ }^{22}$ E. S. Dizon, A. E. Hicks, and V. E. Chirico, Rubber Chem. Technol. 47, 231 (1974).

${ }^{23}$ G. R. Hamed, Rubber Chem. Technol. 56, 244 (1983).

${ }^{24}$ K. F. Gazeley, A. D. T. Gorton, and T. D. Pendle, in "Natural Rubber Science and Technology," A. D. Roberts, Ed., Oxford University Press, New York, 1988, Chapter 3.

${ }^{25}$ I. S. Choi and C. M. Roland, Rubber Chem. Technol. 69, 591 (1996).

${ }^{26}$ R. L. Cormia, F. P. Price, and D. Turnbull, J. Chem. Phys. 37, 13433 (1962).

${ }^{27}$ J. P. Mercier, Polym. Eng. Sci. 30, 270 (1990).

${ }^{28}$ Y. Shimomura, J. L. White, and J. E. Spiruiell, J. Appl. Polym. Sci. 27, 3553 (1982).

${ }^{29}$ A. N. Gent, Trans. Inst. Rubber Ind. 30, 139 (1954).

${ }^{30}$ A. N. Gent, J. Polym. Sci. 18, 321 (1955).

${ }^{31}$ M. J. Brock and M. J. Hackathorn, Rubber Chem. Technol. 45, 1303 (1972).

${ }^{32}$ Y.-J. Chen, J. L. White, K. Min, N. Nakajima, and F. C. Weissert, Rubber Chem. Technol. 61, 324 (1988).

${ }^{33}$ D. R. Burfield, Polymer 25, 1823 (1984).

${ }^{34}$ S. Kawahara, Y. Isono, T. Kakubo, Y. Tanaka, and E. Aik-Hwee, Rubber Chem. Technol. 73, 39 (2000).

${ }^{35}$ I. S. Choi and C. M. Roland, Rubber Chem. Technol. 70, 202 (1997).

${ }^{36}$ P. W. Allen and K. P. Jones, in "Natural Rubber Science and Technology," A. D. Roberts, Ed., Oxford University Press, New York, 1988, Chapter 1.

${ }^{37}$ F. S. Nakayama, W. W. Schloman, and S. F. Thames, in "New Crops, New Uses, New Markets-1992 Yearbook of Agriculture," U.S. Supt. of Docs., Washington, D.C., 1992, Chapter 15.

38“Guayule-Natural Rubber: A Technical Publication with Emphasis on Recent Findings," J. W. Whitworth and E. E. Whitehead, Eds., Guayule Administrative Management Committee and U.S. Dept. Agriculture Cooperative State Research Service, Office of Arid lands Studies, Tucson, AZ, Univ of Arizona, 1991.

${ }^{39}$ D. McIntyre, H. L. Stephens, and A. L. Bhowmick, in "Handbook of Elastomers," A. K. Bhowmick and H. L. Stephens, Eds., Marcel Dekker, Inc., New York, 1988, Chapter 1.

${ }^{40}$ F. S. Nakayama, in "Natural Rubber: Developments in Crop Science, 23," M. R. Sethuraj and N. M. Mathew, Eds., Elsevier, New York, 1992, Chapter 25.

${ }^{41}$ F. A. Eagle, Rubber Chem. Technol. 54, 662 (1981).

${ }^{42}$ L. S. Porter and H. L. Stephens, Rubber Chem. Technol. 52, 361 (1979).

${ }^{43}$ L. F. Ramos De Valle, Rubber Chem. Technol. 54, 24 (1981).

${ }^{44}$ L. F. Ramos De Valle, J. Polym. Eng. 5, 259 (1985).

${ }^{45}$ A. N. Gent, in “Science and Technology of Rubber," 2nd ed., J. E. Mark, B. Erman, and F. R. Eirich, Eds., Academic Press, New York, 1994, Chapter 10. 
${ }^{46}$ G. J. Lake, Rubber Chem. Technol. 68, 435 (1995).

${ }^{47}$ A. Kadir, Ph.D. thesis, Univ. of London, 1980.

${ }^{48}$ G. J. Lake, Prog. Rubber Technol. 45, 89 (1983).

${ }^{49}$ P. B. Lindley, J. Strain Anal. 7, 132 (1972).

${ }^{50}$ H. W. Greensmith, J. Appl. Polym. Sci. 7, 993 (1963).

${ }^{51}$ A. G. Thomas, J. Polym. Sci. 31, 467 (1958).

52 A. N. Gent, P. B. Lindely, and A. G. Thomas, J. Appl. Polym. Sci. 8, 455 (1964).

${ }^{53}$ P. J. Flory, N. Rabjohn, and M. C. Schaffer, J. Polym. Sci. 4, 435 (1949).

${ }^{54}$ G. R. Taylor and S. R. Darin, J. Polym. Sci. 17, 511 (1955).

${ }^{55}$ A. M. Bueche, J. Polym. Sci. 19, 275 (1956).

${ }^{56}$ F. Bueche, J. Polym. Sci. 24, 189 (1957).

57 J. H. A. Grobler and W. M. McGill, J. Polym. Sci., Polym. Phys. Ed. 32, 287 (1994).

${ }^{58}$ D. Parkinson, "Reinforcement of Rubbers," Lakeman and Co. for the Institution of the Rubber Industry, London, 1957.

${ }^{59}$ A. I. Medalia, Rubber Chem. Technol. 60, 45 (1987).

${ }^{60}$ H. Liu, R. F. Lee, and J. A. Donovan, Rubber Chem. Technol. 60, 893 (1987).

${ }^{61}$ G. R. Hamed and H. J. Kim, Rubber Chem. Technol. 72, 895 (1999).

${ }^{62}$ G. R. Hamed and B. H. Park, Rubber Chem. Technol. 72, 946 (1999).

${ }^{63}$ H. Liu, R. F. Lee, and J. A. Donovan, Rubber Chem. Technol. 60, 893 (1987).

${ }^{64}$ L. Mullins, in "The Chemistry and Physics of Rubber-Like Substances," L. Bateman, Ed., Maclaren and Sons, New York, 1963.

65 “The Natural Rubber Formulary and Property Index,” Malaysian Rubber Producers' Research Association, Brickendonbury, England, 1984.

${ }^{66}$ ASTM Standard D 2240-86, "Standard Test Method for Rubber Property—Durometer Hardness," Annu. Book of Stand. 09.01, 434 (1991).

${ }^{67}$ A. G. Thomas and J. M. Whittle, Rubber Chem. Technol. 43, 222 (1970).

${ }^{68}$ G. R. Hamed, Rubber Chem. Technol. 67, 529 (1994).

${ }^{69}$ K. Grosch, J. A. C. Harwood, and A. R. Payne, Nature 212, 497 (1966).

${ }^{70}$ L. Mullins, Trans. Inst. Rubber Ind. 32, 231 (1956). 